\title{
Que rostos da escola emergem quando em frente ao espelho
}

Marcelo Vicentin ${ }^{1}$

Isabel Cristina dos Santos Rodrigues ${ }^{2}$

\section{Resumo}

Este trabalho apresenta o conceito de heterotopia arquitetado por Michel Foucault, entre 1966 e 1967 , na problematização das relações de saber na emergência de discursos e relações de poder no plano dos espaços. Para tanto, primeiramente, apresenta a construção do termo heterotopia pelo autor em contra oposição à utopia. Na sequência, com o aporte do conceito de "rosto", proposto por Giorgio Agamben, manifesta-se a heterotopia como operador conceitual, ferramenta que se constitui a partir da prática, inserindo-se na ordem do saber, da verdade, do discurso, dos espaços, contestando os jogos de poder escolares por meio de rostos assimétricos e dissonantes, com efeitos sobre a escola, seu saber; sobre nós mesmos.

Palavras-chave: Escola; Heterotopia; Utopias.

\section{What faces of the school emerge when in front of the mirror}

\begin{abstract}
:
This paper presents the concept of heterotopia designed by Michel Foucault between 1966 and 1967, in the problematization of the relations of knowledge in the emergence of discourses and power relations in the space plane. For this, first, it presents the construction of the term heterotopia by the author in opposition to utopia. In the sequence, with the contribution of the concept of "face", proposed by Giorgio Agamben, heterotopia is manifested as conceptual operator, a tool that is constituted from the practice, inserting itself in the order of knowledge, truth, of the spaces, contesting the school power games through asymmetrical and dissonant faces, with effects on the school, their knowledge; about ourselves.

Keywords: School; Heterotopia; Utopias.
\end{abstract}

\section{Considerações iniciais}

Michel Foucault utilizou o termo heterotopia em três textos, todos do final da década de 1960. O termo aparece pela primeira vez em suas obras no prefácio de As Palavras e as Coisas (1966/2000), livro que segundo o autor, em aberta referência e influência, nasceu de um texto do escritor argentino Jorge Luis Borges, O Idioma Analítico de John Wilkins; do riso perturbador e inquietante perante certa ordem do pensamento, da classificação de animais presente na

\footnotetext{
${ }^{1} \mathrm{O}$ autor contou com apoio da Coordenação de Aperfeiçoamento de Pessoal de Nível Superior - Brasil (CAPES) Código de Financiamento 001. Pós-doutorando do programa Stricto Sensu em Educação da Universidade São Francisco, apoio da Coordenação de Aperfeiçoamento de Pessoal de Nível Superior - Brasil (CAPES) -São Paulo, marcelovicentin@yahoo.com.br

2 Professora da Faculdade Zumbi dos Palmares, São Paulo, isaisabelrodrigues@gmail.com
}

Periódico Horizontes - USF - Itatiba, SP - Brasil - e019027 
enciclopédia chinesa Empório Celestial de Conhecimento Benevolente.

Em suas remotas páginas consta que os animais se dividem em (a) pertencentes ao Imperador, (b) embalsamados, (c) amestrados, (d) leitões, (e) sereias, (f) fabulosos, (g) cães soltos, (h) incluídos nesta classificação, (i) que se agitam como loucos, $(j)$ inumeráveis $(k)$ desenhados com um finíssimo pincel de pêlo de camelo, $(\mathrm{l})$ etcétera, $(\mathrm{m})$ que acabam de quebrar o vaso, $(\mathrm{n})$ que de longe parecem moscas (BORGES, 2000, p.76-77).

A palavra heterotopia aparece apenas duas vezes no prefácio do livro, ambas na mesma página e parágrafo, na oposição entre heterotopia e utopia, para afirmar as heterotopias como o que inquieta, faz rir, arruína, provoca tremores na ordem reinante; particularmente sobre a linguagem, a sintaxe, a gramática, a proximidade entre palavras e coisas.

As utopias consolam: é que, se elas não têm lugar real, desabrocham, contudo, num espaço maravilhoso e liso; abrem cidades com vastas avenidas, jardins bem plantados, regiões fáceis, ainda que o acesso a elas seja quimérico. As heterotopias inquietam, sem dúvida porque solapam secretamente a linguagem, porque impedem de nomear isto e aquilo, porque fracionam os nomes comuns ou os emaranham, porque arruínam de antemão a "sintaxe" e não somente aquela que constrói as frases - aquela, menos manifesta, que autoriza "manter juntos" (ao lado e em frente umas das outras) as palavras e as coisas. Eis porque as utopias permitem as fábulas e os discursos: situam-se na linha reta da linguagem, na dimensão fundamental da fábula; as heterotopias (encontradas tão frequentemente em Borges) dessecam o propósito, estancam as palavras nelas próprias, desde a raiz, toda a possibilidade de gramática; desfazem os mitos e imprimem esterilidade ao lirismo das frases (FOUCAULT, 2000, p. XIII).

O termo heterotopia reaparece no final de $1966^{3}$ em um par de conferências radiofônicas, para as quais Foucault fora convidado para falar sobre "utopia e literatura". O convite para as conferências estava embalado pelo lançamento e curiosidade despertada por As Palavras e as Coisas (DEFERT, 2013). Deste modo, em Utopie et Héterotopies, apresentou sua visão sobre a utopia e a heterotopia.

Na primeira conferência, O Corpo Utópico, Foucault localiza no corpo humano a origem e o ator de todas as utopias, que têm por finalidade produzir fábulas sobre a potência de um corpo

\footnotetext{
${ }^{3}$ Dias 07 e 21 de dezembro de 1966.

Periódico Horizontes - USF - Itatiba, SP - Brasil - e019027
} 
que nega sua dimensão, sua estética e sua temporalidade. A segunda conferência, As Heterotopias, abandona a análise anterior sobre discursos, linguagem e saberes, e se ocupa de problematizar os espaços, espaços-tempos, quer provisórios quer, ao contrário, cumulativos, "lugares onde estou e não estou, como o espelho e o cemitério; ou onde sou outro [...]. Eles ritualizam cortes, limiares, desvios e os localizam" (DEFERT, 2013, p.39). Os programas originaram o convite para a conferência Outros Espaços, proferida no Círculo de Estudos Arquitetônicos ${ }^{4}$ de Paris, em 14 de Março de 1967. No texto desta conferência, Foucault reafirma as relações entre heterotopia e espaços, e a oposição em relação à utopia.

Entretanto, o conceito de heterotopia ficou reduzido às duas menções presentes no prefácio de As Palavras e as Coisas por quase 20 anos. A publicação da conferência de 1967, Outros Espaços, só foi autorizada pelo autor pouco antes de sua morte, em 1984, ano também da publicação textual da conferência na revista Architecture, Mouvement, Continuité ${ }^{5}$. As conferências Utopies et Héterotopies tiveram os áudios editados e disponibilizados em 2004 e publicados em $2009^{6}$.

Com a autorização para publicação de Outros Espaços, o termo heterotopia foi incluído na caixa de ferramentas do autor e posto a funcionar por comentadores e pesquisadores, indo ao encontro do seu desejo de ser mais utilizado do que lido. No Brasil, a ferramenta heterotopia ressoa nas produções de diversos pesquisadores ${ }^{7}$, como nas dos autores deste texto ${ }^{8}$, em problematizações sobre a escola e o currículo, de como as coisas funcionam e/ou acontecem, ensaiando alternativas para espaços, corpos e discursos.

\section{Afinal! O que é essa tal heterotopia?}

No diálogo entre Foucault e Gilles Deleuze em Os Intelectuais e o Poder (1972/2015), o porto seguro dos intelectuais e das teorias se encontra abalado pela necessidade de se colocar

\footnotetext{
${ }^{4}$ Des Espaces Autres, Cercle D'Étude Architecturales.

${ }^{5}$ Architecture, Mouvement, Continuité, n. 5, de outubro de 1984, p. 46-49.

${ }^{6}$ Le corps utopique, les hétérotopies. Nouvelles Éditions Lignes, 2009.

${ }^{7}$ Gallo (2015, 2013); Gallo e Figueiredo (2015); Passetti (2005, 2003, 2002); Rago (2015, 2013); Veiga-Neto (2007, 2002); entre outros.

${ }^{8}$ Vicentin (2018, 2013); Vicentin, Mendes e Monteiro (2014); Vicentin e Rodrigues (2018).
} 
em posição de combate direto contra o poder, "de lutar contra as formas de poder ali onde ele é, ao mesmo tempo, o objeto e o instrumento disso: na ordem do 'saber', da 'verdade', da 'consciência', do 'discurso'” (FOUCAULT, 2015, p.38). Por conseguinte, a teoria deverá se constituir a partir da prática, dos embates contra as práticas do poder, tornar-se, de acordo com Deleuze uma ferramenta que funcione, que tenha uso: "se não há pessoas para dela se servirem, a começar pelo próprio teórico que cessa então de ser teórico, é porque ela não vale nada, ou porque o momento ainda não chegou" (FOUCAULT, 2015, p.38).

Heterotopia faz parte da caixa de ferramentas de Foucault, ferramenta que provoca um riso perturbador sobre a organização e ordenamento do mundo, descortinando o modo como o vemos e o pensamos; heteróclitos, de uma estranheza destoante à ordem natural e retilínea do mundo, rompendo com certa distinção simétrica e familiar própria de uma matriz racional e moral.

Portanto, heterotopias problematizam os modos de pensar, a produção de saberes, atravessando os espaços constituídos e produzidos pelos códigos fundamentais de uma cultura (linguagem, percepção, trocas, técnicas, valores), as teorias científicas e interpretações filosóficas. Espaços de/para múltiplas variáveis e (in)coerências, pois arbitrárias e contingentes. Contudo, a ordem que se impõe aos discursos e aos espaços, busca apagar o riso provocado por Borges, o riso demolidor dos loucos e dos cínicos, que insistem em ver e dizer coisas que aparentemente não estão visíveis ou audíveis. Destarte, heterotopia como ferramenta, chave para o múltiplo, do não conhecido existente no conhecido, ferramenta de embate entre uma ordem que se quer onipresente e outras que desarranjam, provoca desordem, fazendo "cintilar os fragmentos de um grande número de ordens possíveis" (FOUCAULT, 2007, p. XII), embaraçando a categorização das coisas em lugares-comuns, gerando ruídos nos entrecruzamentos, nas fronteiras da/entre linguagem, do discurso, do corpo, do espaço.

Foucault, em O Corpo Utópico (1966/2013), escreve que as utopias nascem do próprio corpo e o corpo é o grande ator utópico, pois é o ponto zero do mundo, lugar de onde partem todos os discursos e lugares possíveis, reais ou utópicos. Entretanto, para o autor (2002, 2009, 2013), as utopias estão posicionadas em lugares não reais, espaços fora de todos os lugares, com a intencionalidade de encobrir-nos, de produzir um corpo que se quer desconhecer. Em contraoposição, as heterotopias buscam desvelar os embates, o que de arbitrário e contingente está presente, rompendo com um mundo retilíneo, pronto e unificado; espaços, discursos 
singulares com produções diferentes ou mesmo opostas.

As utopias são os posicionamentos sem lugar real. São posicionamentos que mantêm com o espaço real da sociedade uma relação geral de analogia direta ou inversa. É a própria sociedade aperfeiçoada ou é o inverso da sociedade mas, de qualquer forma, essas utopias são espaços que fundamentalmente são essencialmente irreais. Há igualmente, e isso provavelmente em qualquer cultura, em qualquer civilização, lugares reais, lugares efetivos, lugares que são espécies de contraposicionamentos, espécies de utopias efetivamente realizadas nas quais os posicionamentos reais que se podem encontrar no interior da cultura estão ao mesmo tempo representados, contestados e invertidos, espécies de lugares que estão fora de todos os lugares, embora eles sejam efetivamente localizáveis. Esses lugares, por serem absolutamente diferentes de todos os posicionamentos que eles refletem e dos quais eles falam, eu, os chamarei, em oposição às utopias, de heterotopias (FOUCAULT, 2009, p.414-415).

Consequentemente, as heterotopias como experiências descontínuas e múltiplas nas relações com o espaço e com a linguagem possibilitam ordenações, visões de mundo arbitrárias e assimétricas, tal como nos ensina Borges (2000, p.76): "não há classificação do universo que não seja arbitrária e conjetural. A razão é muito simples: não sabemos o que é o universo. [...] pode-se suspeitar que não há universo no sentido orgânico, unificador, que tenha essa ambiciosa palavra".

Como as heterotopias não se alinham a espaços e tempo universais, produzem - e é produto de torções e dobras - múltiplos posicionamentos, discursos e práticas que embaralham as relações de poder e subjetivação; porquanto, produzem outras cartografias para a ordem das coisas e do saber, emergindo um "conhecimento [que] é produto do embate de forças [... de] vários espaços em um único local" (TOPINKA, 2010, p. 56). Na justaposição, no alinhamento desses múltiplos, ilumina-se a ordem de um saber, a violência de sua emergência perante outros modos de conhecimentos, outros espaços.

\section{A caixa de ferramenta}

Para que o pensamento de autores como Foucault e Deleuze sejam postos em uso, utilizados como ferramentas a fim de produzir outros pensamentos e interferir concretamente sobre a realidade, Gallo (2017) propõe que a partir da ideia de caixa de ferramentas sejam tomados como "operadores conceituais". Entretanto, estes não podem se confundir com 
"operadores metodológicos".

Muito mais do que Deleuze, Foucault se ocupou dos conceitos e dos métodos investigativos: como fazemos pesquisa? Como pensamos? Seguindo seus passos, penso que podemos falar, também, sobre 'operadores metodológicos', os quais não podem ser confundidos com os operadores conceituais. Se estes são ferramentas prontas para nosso uso teórico-conceitual, os operadores metodológicos são ferramentas para fazer pesquisa, são formas de agir e pensar, são o estabelecimento de protocolos de atividade investigativa. Assim podemos dispor de caixas de ferramentas de dois tipos: ferramentas conceituais e ferramentas metodológicas. Podemos pensar com Foucault, com seus conceitos e a partir deles produzir novas ideias e novos conceitos; mas podemos também pensar do mesmo modo que Foucault, isto é, usando suas ferramentas metodológicas pensar coisas que ele não pensou, para nos dedicarmos ao nosso problema investigativo. Problemas investigativos que podem ser analisados com as ferramentas propostas e organizadas por Foucault. Em outras palavras, trabalhar como fez Foucault (GALLO, 2017, p.50, tradução nossa) ${ }^{9}$.

Discurso, arquivo, episteme, saber-poder, disciplina, biopoder, dispositivo, técnicas de si, cuidado de si, parresía, psicagogía, aleturgia e ontologia do presente, são alguns dos operadores conceituais listados por Gallo (2017). Como exemplo de operador metodológico, a anarqueologia, que muda o centro do pensamento de Foucault da relação poder-saber para o governo dos homens pela verdade, como também em relação com a filosofia política tradicional: "enquanto este coloca o vínculo do sujeito com a verdade como determinante em sua relação com o poder, a anarqueologia de Foucault inverte essa questão e põe o poder como determinante para a relação do sujeito com a verdade ${ }^{10 \prime \prime}(p .63)$.

Ao conjunto de operadores conceituais listados por Gallo, acrescentamos a heterotopia, que emerge conceitualmente no movimento metodológico da arqueologia como ferramenta

\footnotetext{
${ }^{9}$ Mucho más que Deleuze, Foucault se ha ocupado, además de los conceptos, de los métodos investigativos: ¿cómo hacemos investigación? ¿Cómo pensamos? Tras sus huellas, pienso que podemos hablar, también, de "operadores metodológicos" los cuales no se pueden confundir con los operadores conceptuales. Si estos últimos son herramientas que encontramos listas para nuestro uso teórico-conceptual, los operadores metodológicos son herramientas para hacer investigación, son maneras de actuar y de pensar, son el establecimiento de protocolos de actividad investigativa. De manera que podemos disponer de cajas de herramientas de dos tipos: herramientas conceptuales y herramientas metodológicas. Podemos pensar con Foucault, con sus conceptos y a partir de ellos producir nuevas ideas y nuevos conceptos; pero podemos también pensar al modo de Foucault, esto es, utilizar sus herramientas metodológicas para pensar cosas que él no pensó, para dedicarnos a nuestros problemas investigativos. Problemas investigativos que pueden ser analizados con las herramientas propuestas y dispuestas por Foucault. En otras palabras, trabajar como lo hizo Foucault.

${ }^{10}$ En cuanto esta coloca el vínculo del sujeto con la verdad como determinante en relación a su vínculo con el poder, la anarqueología de Foucault invierte la cuestión y pone el vínculo con el poder como determinante de la relación del sujeto con la verdad.
}

Periódico Horizontes - USF - Itatiba, SP - Brasil - e019027 
para descentrar a ordem do saber e, ao mesmo tempo, ao reorientar a ferramenta para o espaço, antecipa o movimento metodológico da genealogia e das suas relações com o poder. Defert (2013) observa que "as análises foucaultianas do espaço recebem uma visibilidade nova como lugar de uma dupla articulação do poder sobre o corpo do indivíduo e do saber ao poder" (p.4647) e, deste modo, o pensamento de Foucault influencia os que problematizam o espaço urbano.

Como operador conceitual, a heterotopia permite-nos tanto colocar em suspensão a ordem dos saberes, bem como o ordenamento dos espaços reais; logo, ferramenta precisa e adequada para problematizar espaços, como o escolar, visto que a escola está alicerçada em suas características disciplinares, como Foucault apresentou em Vigiar e Punir (1975/2011a).

Como espaço real - um topos com arquitetura física e discursiva -, a máquina pedagógica movimenta tecnologias e táticas de poder que auxiliam na manifestação e sustentação da ordenação de um modo de ver, perceber e produzir signos e significados sobre o mundo social, político, econômico, cultural. Sob seu beneplácito: condução, coerção, normalização, disciplinamento, ritualização, subjetivação, assujeitamento do eu.

\section{Rostos no espelho de Foucault}

Foucault (2009) metaforiza o espelho para problematizar o saber e os espaços, para discutir seus movimentos interiores e exteriores, o dentro e o fora, os embates entre o mesmo e seus simulacros, o mesmo e seus outros.

O espelho, afinal, é uma utopia, pois é um lugar sem lugar. No espelho, eu me vejo lá onde não estou, em um espaço irreal que se abre virtualmente atrás da superfície, eu estou lá longe, lá onde não estou (...): utopia do espelho. Mas é igualmente uma heterotopia, na medida em que o espelho existe realmente, e que tem, no lugar que ocupo, uma espécie de efeito retroativo; é a partir do espelho que me descubro ausente no lugar em que estou porque eu me vejo lá longe. A partir desse olhar que de qualquer forma se dirige para mim, do fundo desse espaço virtual que está do outro lado do espelho, eu retorno a mim e começo a dirigir meus olhos para mim mesmo e a me constituir ali onde estou; o espelho funciona como uma heterotopia no sentido em que ele torna esse lugar que ocupo, no momento em que me olho no espelho, ao mesmo tempo absolutamente real, em relação com todo o espaço que o envolve (FOUCAULT, 2009, p.415).

Periódico Horizontes - USF - Itatiba, SP - Brasil - e019027 
As diferenças entre heterotopia e utopia ocorrem no domínio do tempo: uma relação com o presente, sobre o posto e não com o porvir; no domínio do conteúdo: do não conhecido no conhecido, no sabor acre e azedo ao doce gosto das utopias. A justaposição de espaços, outras moldagens espaciais à novos espaços, de tal modo que essas alternativas espaciais colidem sobre o ordenamento dominante: a emergência de contraespaços, contrapoderes e resistências, um outro em relação ao poder; um outro no interior do próprio poder, que o contesta; parte do mesmo poder e não algo que lhe é exterior.

Por conseguinte, se o poder está em todo lugar, contracondutas, contraespaços e resistências também estão. Porquanto, por meio da heterotopia, a emergência de reflexos da mesma e de outras ordens; a emergência de um embate pela supremacia do território dos sentidos e significações; alternativas à ordem dominante. Batalhas são vencidas, mas a guerra não se encerra: canhões ladram; o espelho embaça, fantasmas refletidos, o risco de estilhaçar-se.

Elas [as heterotopias] são a contestação de todos os outros espaços, uma contestação que pode ser exercida de duas maneiras: (...) criando uma ilusão que denuncia todo o resto da realidade como ilusão, ou, ao contrário, criando outro espaço real tão perfeito, tão meticuloso, tão bem disposto quanto o nosso é desordenado, mal posto e desarranjado (FOUCAULT, 2013, p. 28).

Ao mirar-se o espelho, olhos nos olhos, reflexo de olhos, outros olhos, rostos, espectros, fantasmagorias; a possibilidade e problematizações de verdades, outras verdades escondidas no mesmo espaço, corpo, espaço-corpo; verdades dissimuladas, infames; outra, talvez mesma, história.

Nesse jogo de espelhos, de olhares espelhados, de miragens, a procura por reflexos: rostos que quando revelados, como escreve Agamben (1996), revelam a linguagem, traduzemse pela palavra. Tragicômica, a linguagem, "não tem, consequentemente, nenhum conteúdo real, não diz a verdade sobre esse ou aquele estado da alma ou de fato, sobre esse ou aquele aspecto do homem ou do mundo: é unicamente abertura, unicamente comunicabilidade" (AGAMBEN, 1996, p.74, tradução nossa) $)^{11}$

Rostos que expõem o homem, que para se distinguir e reconhecer "separa a imagem das

\footnotetext{
${ }^{11}$ Essa non ha, perciò, alcun contenuto reale, non dice il vero su questo o quello stato d'animo o di fatto, su questo o quell'aspetto dell'uomo o del mondo: è soltanto apertura, soltanto comunicabilità.
} 
coisas, dá-Ihe um nome" (AGAMBEN, 1996, p.75, tradução nossa) ${ }^{12}$, que ordenam pela palavra a natureza, as coisas, o mundo, na exposição deste rosto. Porquanto, um campo de batalha pela ordenação das coisas do mundo, visto que a exposição é o lugar da política, lugar sem zona definida para os conflitos pela exposição da verdade, de sua própria verdade.

O rosto não é simulacro, no sentido de algo que esconde ou encobre a verdade: é simultas, o estar-junto de múltiplos rostos que o constituem, sem que nenhum deles seja mais verdadeiro do que outros. Apreender a verdade do rosto significa não compreender a semelhança, mas a simultaneidade dos rostos, a potência inquieta que os mantém unidos e os unifica (AGAMBEN, 1996, p.79, tradução nossa) $)^{13}$.

Por conseguinte, o rosto que emerge na linguagem das coisas para Agamben, tal qual a heterotopia para Foucault, é a potência que profana o conhecimento que se quer estável, estabilizado, limpo de uma história sempre conflituosa e sangrenta.

\section{Um rosto heterotópico para a escola}

A escola moderna, esconde sob seus alicerces o sangue dos embates que culminaram no seu estabelecimento, na sua ordenação: as dominações, as relações de poder, as práticas de condução e coerção que asseveraram verdades e conhecimentos. Côncavo ou convexo, o espelho posto a sua frente, reflete uma verdade "produzida e transmitida sob controle, não exclusivo, mas dominante, de alguns grandes aparelhos políticos ou econômicos" (FOUCAULT, 2011b, p.13), que por meio de efeitos do poder mantêm a ordem e faz a sociedade funcionar.

Sob os reflexos desses movimentos do poder, vinculados a mecanismo e práticas de produção, a escola empareda seus sujeitos entre funções e normas, desejos e necessidades que confluem para a produção de certos signos, regras e conflitos: um saber possível que subjetiva e produz um homem de dever e racionalidade, e os limites de própria liberdade deste homem.

De frente ao espelho, exposto à luz, um rosto tem uma miríade de reações: inveja, ódio,

\footnotetext{
12 Separa le immagini dalle cose, dà loro un nome

13 Il volto non è simulacro, nel senso di qualcosa che dissimula e copre la verità: esso è la simultas, l'essere-insieme dei molteplici visi che lo costituiscono, senza che alcuno di essi sia più vero degli altri. Cogliere la verità del volto significa afferrare non la somiglianza, ma la simultaneità dei visi, l'inquieta potenza che li tiene insieme e accomuna.
}

Periódico Horizontes - USF - Itatiba, SP - Brasil - e019027 
felicidade, alegria. O rosto da escola quando também em frente ao espelho, iluminado, reflete suas sensações, seus espectros, as amplas emoções que o atravessam. De acordo com Agamben (1996), um rosto iluminado, dito, constituído pela linguagem, pela palavra (que não é a verdade sobre a alma, o homem, o mundo), preenche-se de comunicabilidade, do político, de uma verdade que faz emergir não o simulacro, mas o que de simultâneo esculpe este rosto.

A heterotopia também ocupa o domínio do simultâneo, o embate entre discursos por um território: conflitos soterrados pelos simulacros do discurso dominante. Por consequência, ao revelar-se um rosto, a produção de linhas de fuga, heterotopias, fendas escolares, que, entretanto, são abafadas pelo discurso dominante. Foucault (1994c) escreve que não há coisa da ordem da libertação e outras da opressão, pois todo sistema tem possibilidades de resistências, desobediências, oposições, contracondutas.

Não penso que exista algo que seja funcionalmente - pela sua própria natureza - absolutamente libertador. A liberdade é uma prática. [...] A liberdade do homem nunca é assegurada pelas instituições e leis destinadas a garanti-las. E esta é a razão pela qual quase todas estas leis e instituições estão sempre aptas a serem viradas ao contrário. Não porque são ambíguas, mas simplesmente porque a 'liberdade' é aquilo que se deve exercer. [...] Se pudéssemos encontrar um lugar, e talvez haja alguns, onde a liberdade é efetivamente exercida, descobriria que tal não se deve à ordem dos objetos, mas, uma vez mais, devese a uma prática da liberdade [...] A liberdade é o que se deve exercer, a garantia da liberdade é a liberdade. [...] Os homens sonharam com máquinas libertadoras. Mas, por definição, não existem máquinas de liberdade (FOUCAULT, 1994b, p.275 -277, tradução nossa) ${ }^{14}$.

No espelho, na imagem refletida da escola, o embate pela presença do que de arbitrário, contingente a escola carrega em si; sob seus alicerces, cotidianamente micro guerrilhas, micro poderes, contracondutas a alvejá-la; em seu reflexo, modos outros de perceber e sentir a educação e a escola, valores outros soterrados por documentos e valores que movimentam uma certa ordem do mundo; "discursos em disputa que proporcionam que a escola, pelos

\footnotetext{
${ }^{14}$ Je ne crois pas, en revanche, a l' existence de quelque chose qui serait fonctionnellement - par sa vraie nature radicalement libérateur. La liberté est une pratique. [...] la liberté des hommes n'est jamais assurée par les institutions et les lois qui ont pour fonction de la garantir. C'est la raison pour laquelle on peut, en fait, tourner la plupart de ces lois et de ces institutions. Non pas parce qu'elles sont ambiguës, mais parce que la 'liberté' est ce qui doit s'exercer [...] Les hommes ont reve de machines liberatrices. Mais il n'y a pas, par définition, de machines de liberté. Ce qui ne veut pas dire que l'exercice de la liberte soit totalement insensible a la distribution de l'espace, mais cela ne peut fonctionner que là où il y a une certaine convergence; lorsqu'il y a divergence ou distorsion.
}

Periódico Horizontes - USF - Itatiba, SP - Brasil - e019027 
subterrâneos e pela superfície, não conheça calmarias eternas; e as crises não sejam o retrato de sua agonia, mas da agonística cotidiana de sua existência" (VICENTIN, 2018).

Porquanto, sob o espelho, o rosto da escola e suas imagens se movimentam, embatem, guerreiam sem armas, sem palavras acordadas que erodem a tranquilidade da norma. A ausência de uma forma pronta, definida e/ou institucionalizada, promove, favorece outras rotas, ritmos, variações, heterogeneidade, diferenças, alternativas, invenções, experimentações de modos outros de vida, de estilos de vida de onde pode emergir uma cultura e uma ética.

\section{Considerações finais}

Heterotopias, como as utopias, emergem do corpo e como tal criadas pela arbitrariedade humana: invenções e criações que articulam as percepções, o imaginário, os saberes, o visível, o enunciável; normas, morais, ciências, discursos. Corpo-imã, de atração/repulsão; corpoterritório, em disputa; corpo-poder; que domina e é dominado; corpo- sentidos, que revelam e projetam imagens, realidades do que nos cercam; corpo despedaçado, segmentado, visível em partes, "que conhece sua totalidade apenas naquilo que o reflete: outro corpo, corpo-espelho que reflete outro possível eu" (VICENTIN, 2018).

Para Foucault (2013), o primeiro princípio das heterotopias é sua permanente existência no mundo através das mais diferentes sociedades, pois elas incomodam os mitos, as universalidades, a ordem, as regras, a realidade, provocando dobras que se voltam a si e arrombam com nossas neutralidades, provocando o mesmo riso perturbador que Borges provocou em Foucault (2000), germinando descontinuidades e rupturas.

Não há, provavelmente, nenhuma sociedade que não constitua sua heterotopia ou suas heterotopias. Esta é, sem dúvida, uma constante de todo grupo humano. Na verdade, porém, essas heterotopias podem assumir, e assumem sempre, formas extraordinariamente variadas, e talvez não haja, em toda superfície do globo ou em toda história do mundo, uma única forma de heterotopia que tenha permanecido constante (FOUCAULT, 2013, p.21).

Por isso, ao tomar a heterotopia como operador conceitual, procuramos por reinventar os espaços, as posições-sujeitos no constituído; a heterotopia provocando rupturas, perturbando 
a ordem aparente, desestabilizando o princípio de unidade que parece reger o espaço escolar; mostrar o caos que está presente à ordem. Um diminuir de fronteiras entre o nós e o eles, entre o eu e os meus outros; um perceber o outro e deixar-se perceber pelos outros.

A heterotopia como operador conceitual refletindo o campo pedagógico, refletindo a escola, a fim de que em frente ao espelho não reflita somente a beleza encantatória de Narciso, mas uma miríade de outros rostos, de discursos que a constituem e se embatem violentamente; "as rupturas da vida ordinária, imaginários, representações polifônicas da vida, da morte, do amor, de Eros e Tánatos" (DEFERT, 2013, p.37-38).

Não a calmaria dos mares e dos seus monstros, mas os efeitos de espaços outros, saberes outros sobre nós mesmos. A escola como um barco, como para Foucault (2009), lugar sem lugar, livre e ao mesmo tempo preso ao mar, com vida própria, que desde o século XVI é nossa maior reserva de imaginação, uma heterotopia por excelência, que nos permite brincar, inventar, alucinar, contradizer sem o medo e o terror de uma possível opressão.

\section{Referências}

AGAMBEN, G. II Volto. In: AGAMBEN, G. Mezzi sensa fine: note sulla politica. Torino/Itália: Bollati Boringhieri, 1996, p. 74-80.

BORGES, J. L. O idioma analítico de John Wilkins. In: BORGES, J. L. Jorge Luis Borges - obras completas de Jorge Luis Borges, vol. 2, 1952-1972. Trad. Sérgio Molina. São Paulo: Globo, 2000, p. 75-77.

DEFERT, D. Posfácio. In: FOUCAULT, M. O corpo utópico; as heterotopias. Trad. Salma T. Muchail. 1. ed., São Paulo: N-1, 2013, p.33-55.

FOUCAULT, M. Des espaces autres. Architecture, Mouvement, Continuité, n. 5, out. 1984. p.4649. Disponível em: http://www.articule.net/wp-content/uploads/2008/11/ mfoucaultdesespacesautres.pdf. Acesso em: fev. 2018.

FOUCAULT, M. Espace, savoir et pouvoir. In: DEFERT, D.; EWALD, E; LAGRANGE, J. (Orgs.). Dits et écrits IV. Paris: Gallimard, 1994, p.270-285.

FOUCAULT, M. As palavras e as coisas: uma arqueologia das ciências humanas. Trad. Salma T. Muchail. 8. ed., 2. reimp., São Paulo: Martins Fontes, 2000.

FOUCAULT, M. Outros espaços. In: MOTTA. M. B (Org.). Ditos e escritos III: estética: literatura e Periódico Horizontes - USF - Itatiba, SP - Brasil - e019027 
pintura, música e cinema. Trad. Inês. A. D. Barbosa. 2. ed. Rio de Janeiro: Forense Universitária, 2009, p. 411-422.

FOUCAULT, M. Vigiar e punir: nascimento da prisão. Trad. Raquel Ramalhete. 39. ed. Petrópolis: Vozes, 2011a.

FOUCAULT, M. Verdade e poder. In: MACHADO. R. (Org.). Microfísica do poder. Trad. Roberto Machado. Rio de Janeiro: Graal, 2011b, p.01-14.

FOUCAULT, M. O corpo utópico; as heterotopias. Trad. Salma T. Muchail. 1. ed., São Paulo: N-1, 2013.

FOUCAULT, M. Os intelectuais e o poder. In: MOTTA. M. B (Org.). Ditos e escritos IV: estratégia, poder-saber. Trad. Vera Lucia A. Ribeiro. 3. ed., 2. reimp., Rio de Janeiro: Forense Universitária, 2015, p. 36-45.

GALLO, S. Em torno de uma educação menor: variáveis e variações. 36a Reunião Nacional da ANPEd - 29 de setembro a 02 de outubro de 2013, Goiânia-GO. p.1-12, Disponível em: http://36reuniao.anped.org.br/pdfs_trabalhos_encomendados/gt13_trabencomendado_silvio gallo.pdf. Acesso em: 10 fev. 2019

GALLO, S. La production des hétérotopies à l'école: souci de soi et subjectivation. Le Télémaque, n.47, p.87-96, mai. 2015. Disponível em: https://www.cairn.info/revue-letelemaque-2015-1-page-87.htm. Acesso em: 10 mar. 2019.

GALLO, S. De la anarqueología como operador metodológico. In: CORTÉS, O. P.; BERNAL, O. O. E. (Orgs.). Formas y expresiones metodológicas en el último Foucault. 1. ed., Tunja: Editorial Uptc, 2017, p.43-73.

GALLO, S.; FIGUEIREDO, G. M. Entre maioridade e minoridade: as regiões de fronteira no cotidiano escolar. APRENDER - Caderno de Filosofia e Psicologia em Educação. Vitória da Conquista, n.14, p.25-51, 2015.

PASSETTI, E. Heterotopias anarquistas. Verve, n.2, p.141-173, 2002. Disponível em: https://revistas.pucsp.br/index.php/verve/article/viewFile/4617/3207. Acesso em: 10 fev. 2019.

PASSETTI, E. Vivendo e revirando-se: heterotopias libertárias na sociedade de controle. Verve, n.4, p.32-55, 2003. Disponível em: https://revistas.pucsp.br/index.php/verve/article/ view/4961/3509. Acesso em: 10 fev. 2019.

PASSETTI, E. Foucault libertário: heterotopia, anarquismo e pirataria. In: ANPUH - SIMPÓSIO NACIONAL DE HISTÓRIA, 23., 2005, Londrina. Anais [...]. Londrina: Instituição, 2005. Disponível em: http://www.encontro2014.rj.anpuh.org/resources/anais/anpuhnacional/S.23/ANPUH.S23. 0294.pdf. Acesso em: 10 fev. 2018. 
RAGO, M. Inventar outros espaços, criar subjetividades libertárias. 1.ed., São Paulo: ECidade, 2015.

RAGO, M. A aventura de contar-se: feminismos, escrita de si e invenções de subjetividade. 1. ed., Campinas: Editora da Unicamp, 2013.

TOPINKA, R. J. Foucault, Borges, heterotopia: producing knowledge in other spaces. Foucault Studies. n.9, set. 2010, p.54-70. Disponível em: https://rauli.cbs.dk/index.php/foucaultstudies/article/view/3059. Acesso em: 10. fev. 2018.

VEIGA-NETO, A. De geometrias, currículo e diferenças. Educação \& Sociedade. n.79, p.163-186, ago. 2002.

VEIGA-NETO, A. As duas faces da moeda: heterotopias e emplaziamentos curriculares. Educação em Revista. Belo Horizonte, v.45, p.249-264, jun. 2007.

VICENTIN, M. (Des)construindo o currículo: relações de poder-saber e heterotopias. In: COLÓQUIO NACIONAL MICHEL FOUCAULT, 3., 2013. Uberlândia. Anais [...]. Uberlândia: UFU/Faced, 2013. 1 CD-ROM.

VICENTIN, M.; MENDES, J. R.; MONTEIRO, A. Projeções heterotópicas: do currículo-verdade para o currículo-experiência. In: COLÓQUIO SOBRE QUESTÕES CURRICULARES, 9., 2014. Braga, Portugal. Anais [...]. Braga/Portugal: Universidade do Minho, 2014, p.3664-3668.

VICENTIN, M; RODRIGUES, I. C. R. Corpos que sublevam: sons desarmônicos da guerra. In: FILOSOFIA DA EDUCAÇÃO, 2.; 2018. Rio de Janeiro. Anais [...]. Rio de Janeiro: Uerj, 2018.

VICENTIN, M; Vagas de coisas e palavras: jogos heterotópicos sobre o espaço escola. 2018, 211f. Tese (Doutorado em Educação) - Universidade São Francisco, Itatiba, 2018.

Recebido em março de 2019.

Aprovado em abril de 2019. 